\title{
Vigilance Disorders in Permanent Night Workers: The Case of the Medical Staff
}

\author{
Aouatef Mahfoudh Kraiem 1*, Amira Omrane1, Asma Mahfoudh Boussaid ${ }^{2}$, Imen Kacem¹, \\ Ridha Ben Cheik ${ }^{3}$, Taoufik Khalfallah', Lamia Bouzgarrou' ${ }^{1}$
}

${ }^{1}$ Department of Occupational Medicine and Ergonomics, Faculty of Medicine of Monastir, University of Monastir, Monastir, Tunisia

${ }^{2}$ Department of Physiology, Faculty of Pharmacy, University of Monastir, Tunisia

${ }^{3}$ Department of Physiology, Faculty of Medicine of Monastir, University of Monastir, Monastir, Tunisia

Email: *kraiemaouatef@yahoo.fr

How to cite this paper: Kraiem, A.M., Omrane, A., Boussaid, A.M., Kacem, I., Cheik, R.B., Khalfallah, T. and Bouzgarrou, L. (2017) Vigilance Disorders in Permanent Night Workers: The Case of the Medical Staff. Open Journal of Nursing, 7, 409-418. https://doi.org/10.4236/ojn.2017.73032

Received: July 10, 2016

Accepted: March 28, 2017

Published: March 31, 2017

Copyright (c) 2017 by authors and Scientific Research Publishing Inc. This work is licensed under the Creative Commons Attribution International License (CC BY 4.0).

http://creativecommons.org/licenses/by/4.0/

(c) (i) Open Access

\begin{abstract}
Purpose of the work: To assess the impact of fixed night shift on the vigilance of paramedical staff. Methods: The present study is an exhaustive cross-sectional survey which has been conducted at the University Hospital of Monastir, Tunisia, and it is about 92 care agents working permanently the night. The study of vigilance is based on Epworth scale and Super Lab program. Results: The average age was equal to $42.53 \pm 9.45$ years with a sex ratio of 1.72 . Nurses accounted for $72 \%$. The average score of alertness assessed with Epworth scale was equal to $14.5 \pm 6$. The use of the Super Lab software has objectified a tendency towards the increase in the average time of reaction of accomplishment of the simple task and the positive cueing task, which was evaluated while starting the shift, during the half time of the work and at the end of the shift. In addition, the average rate of errors evaluated at the beginning, half-time and at the end of the work has increased during 3 tests (simple task, positive and negative cueing tasks) without this difference being statistically significant. Conclusion: The alteration of vigilance with an ascent of the error rate among fixed night shift workers is a reality, which puts in question, not only the health of paramedical staff but also the care safety provided by these teams.
\end{abstract}

\section{Keywords}

Impaired Alertness, Fixed Night Work, Healthcare Workers, Epworth Scale

\section{Introduction}

Sleep is a crucial time; it is a fundamental biological need for both physical and mental health. This period of day is necessary for neurons regeneration, consolidation of new memories and formation of new synapses. Sleep deprivation is 
associated with decreased attention and vigilance, with impaired memory and decision making, slower reaction time and increased number of micro sleeps during wakefulness [1]. Prior investigations have demonstrated changes in vigilant attention and cognitive performance with sleep restriction and circadian phase [2] [3]. A meta-analysis of 19 research studies showed impairment in cognition, motor skills, and mood with sleep restriction [4]. Sleep restriction can cause global decreases in brain activity that adversely affects attention [5] [6]. An increased duration of wakefulness is associated with greater adverse effects on vigilant attention [7] [8] and with increasing impairment in psychomotor vigilance as chronic sleep loss accumulates [8] [9]. Circadian phase modulates vigilant performance, with improvements during the circadian day and declines during the circadian night [9].

Sleep deprivation also appears to be associated with other comorbid states such as cardio-vascular diseases [10] [11], metabolic disorders [12] [13]. It may be also associated with emotional lability with increased anxiety and depression [14]. Sleep deprivation is associated with an increased incidence of traffic accidents, comparable to driving under the influence of alcohol [15] [16].

Insufficient sleep due to night work is widely prevalent in our society [17]. These trends may be both more severe and more important in the health care industry, as patient safety can be directly impacted [18]. For nurses, the essence of activity is professional vigilance. It is the mental process that makes the informed nursing actions of assessment, diagnosis, intervention, and evaluation possible and meaningful [19]. Sever study was recognized that extended work hours affected medical [20] [21] and surgical performance [22].

To assure the continuity of care, hospital staff is ever exposed to shift work and for some to permanent night work, which can affect their sleep and vigilance states. So that, we have conducted this exhaustive descriptive study which is interested in hospital employees working permanently at night in a Tunisian university hospital in order to assess the impact of fixed night work on vigilance.

\section{Materials and Methods}

It is an exhaustive cross-sectional study about the hospital staff working fixed night shift hours at University Hospital of Monastir in Tunisia and carried out during three months (April-May-Jun) of 2011.

\subsection{Studied Population}

Study population, who are included in the first step of the study, counted one hundred and five personals. Exclusion criteria were a seniority of fixed night work less than a year and a personal history of sleep disorder. The second step consists on an objective evaluation of vigilance among a representative sample choosing via the table of homogeneous exposition group, that is defined as a group of workers who share the same exposure profile because to determinants involved, such as the environment, employment in the same department, the processes and materials they use and the tasks performed [23]. 


\subsection{Procedure}

Firstly, data collection was realized by a questionnaire filled by the physician investigator while interviewing all participants in order to ensure a good comprehension of questions and to guarantee an answer to the entire questionnaire. Secondly, an objective test of vigilance is performed for a representative group of night work nurses.

\subsection{Measuring Instruments}

\subsubsection{Questionnaires}

Data collection has been carried out thanks to a self-anonymous questionnaire containing two headings. The first topic is related to socio-professional and medical data. These details were in relation with the socio-demographic characteristics (age; gender; marital status; the work of a spouse; the number of supported children), lifestyle (consumption of tobacco and alcohol; the practice of sports activities; participation in family meetings; the distance between the place of work-home and the used means of transport) and occupational characteristics (occupational category; seniority in night shift ...).

The second topic is exploring vigilance using Epworth scale. It is an 8-item selfreport measure of excessive daytime sleepiness that takes several minutes to complete [24]. The ESS distinguishes between good and poor sleepers. Respondents indicate on a four-point Likert-type scale $(0=$ never, $3=$ high chance) the likelihood that they will "doze off or fall asleep" in eight different conditions (e.g., while sitting and reading, riding as a passenger in a car, sitting and talking to someone). Responses are summed to yield a total score from 0 to 24, with higher scores indicating greater sleepiness during common daily activities [25] [26] [27] [28]. ESS total scores of $>10$ have been proposed to indicate excessive daytime sleepiness and four groups will be identified:

- <10: Normal sleepiness.

- 11to 15: Slightly excessive sleepiness.

- 16 to 20: Moderate excessive sleepiness.

- 21 to 24: Significant excessive sleepiness.

\subsubsection{Objective Test of Vigilance}

An objective study of vigilance was carried out among a representative sample of our studied population, calculated according to the theory of homogeneous groups of exposure using "Superlab" software, version 1.5.7. It is a program of exploration of the attentional abilities, based on the study of reaction time (RT) and the errors rate (ER) during the tasks execution included in this software. Three tasks were carried out: a task of simple reaction, a task of positive subscripting, and a task of negative subscripting. For every task, the subject sees a succession of items on the screen and is called to react as quickly as possible to a "target" by pressing the right button.

The evaluation of alertness has been realized by the "Super Lab" software in 3 times: at the beginning of the night shift (between $19-20$ 'o clock), mid-time of the shift (between 24 - 1'o clocks) and at the end of it (5 - 6'o clocks). 


\subsection{Statistical Analysis}

SPSS 11.0 software is used to data entry and the analysis of results. Frequencies and percentages are calculated for the qualitative variables as well as the means, standard deviation, the medians and the extent of extreme values for the quantitative variables.

For the comparison of means, we used Student's t-test for the comparison of two means of independent series and Snedecor's f-test of parametric variance analysis for the comparison of many means. The comparison of frequencies was carried out using Pearson's chi-squared test. A value of $p<0.05$ was regarded as significant.

\section{Results}

\subsection{Sociodemographic Characteristics}

During period study, 92 questionnaires have been collected, with a participation rate of $86.8 \%$. The average age was $42.5 \pm 9.4$ years. The study population has been predominantly male with a sex ratio of 1.72 . The average body mass index was $27.4 \pm 4.7 \mathrm{~kg} / \mathrm{m}^{2}$. Among night workers, $40 \%$ of cases were found to be overweight and $22.8 \%$ were obese. Diabetes and musculoskeletal disorders were the most reported pathological history (16.3\%).

Among the interviewed staff, 37.3\% were smoking and 7.6\% among them reported regular consumption of alcohol. The regular practice of at least a leisure activity has been reported by $22.6 \%$ of cases. Duration of trip [homework] of less than an hour was reported by $82.6 \%$ of cases.

Study population comprised four occupational categories with a predominance of nurses (79.3\%). The average occupational seniority in night shift was of 5 \pm 3.5 years and ranged between 1 and 30 years. Among the fixed night hospital staff, $31.5 \%$ plan to work with the same schedule until the legal retirement age. The occupational characteristics are detailed in Table 1.

\subsection{Vigilance}

\subsubsection{Daytime Sleepiness}

Epworth score mean was of $14.5 \pm 6$. A diurnal excessive somnolence has been noted in $53.2 \%$ of the staff (Table 2). A statistically significant relationship has been noted between Epworth scale, the frequency of family meetings ( $p=0.045)$ and the trip distance home-Hospital $(p=0.026)$.

\subsubsection{Objective Test of Vigilance}

Among the 106 staff permanently working at night, 14 have participated in the objective study of vigilance, using the Super Lab software, and reported to have bout of sleep in $64 \%$ of cases between T2 and T3 of the assessment, ranging from 1 to 5 hours.

During the performance of the task of simple reaction (TSR), the RT has significantly increased between the beginning of the shift and at half-time of it ( $p<$ $0.05)$, whereas it decreased with a statistically significant difference between T1- 
Table 1. Distribution of hospital staff according to their socio-professional characteristics.

\begin{tabular}{|c|c|c|c|}
\hline \multicolumn{2}{|c|}{ Socio-professional characteristics } & \multirow{2}{*}{$\begin{array}{c}\text { Effective } \\
46\end{array}$} & \multirow{2}{*}{$\begin{array}{l}\% \\
50\end{array}$} \\
\hline & $<45$ years & & \\
\hline \multirow[t]{2}{*}{ Age group } & 45 - 55 years & 41.12 & 44.7 \\
\hline & $>55$ years & 4.87 & 5.3 \\
\hline \multirow{3}{*}{ Gender } & Male & 57 & 61.3 \\
\hline & Female & 35 & 38.7 \\
\hline & Single & 20 & 21.7 \\
\hline \multirow{4}{*}{ Matrimonial state } & Married & 70 & 76.1 \\
\hline & Divorced & 1 & 1.1 \\
\hline & Widower & 1 & 1.1 \\
\hline & 0 & 3 & 4.5 \\
\hline \multirow[t]{3}{*}{ Number of dependent children } & $1-3$ & 34 & 74 \\
\hline & $>3$ & 15 & 22.8 \\
\hline & Diabetes & 8 & 8.7 \\
\hline \multirow{5}{*}{ Medical history } & Hypertension & 3 & 3.26 \\
\hline & Musculoskeletal disorder & 7 & 7.6 \\
\hline & Others & 7 & 7.6 \\
\hline & Nurse & 73 & 79.3 \\
\hline & Laboratory agent & 4 & 43 \\
\hline \multirow[t]{4}{*}{ Occupational categories } & Administrator & 1 & 1.1 \\
\hline & Anesthetist technician & 9 & 9.8 \\
\hline & Radiologist technician & 5 & 5.4 \\
\hline & $<10$ years & 25 & 27.2 \\
\hline \multirow[t]{4}{*}{$\begin{array}{l}\text { Average occupational } \\
\text { seniority in night shift }\end{array}$} & $10-20$ years & 5 & 5.4 \\
\hline & $\geq 21$ years & 58 & 65.9 \\
\hline & Age & 29 & 31.5 \\
\hline & Private reasons & 20 & 8.7 \\
\hline \multirow{2}{*}{ Possible pattern for retirement } & Occupational reasons & 8 & 21.7 \\
\hline & Health reasons & 4 & 4.3 \\
\hline
\end{tabular}

Table 2. Distribution of hospital staff according to Epworth score.

\begin{tabular}{ccc}
\hline & Effective & $\%$ \\
\hline Normal sleepiness & 6 & 6.5 \\
Slightly excessive sleepiness & 55 & 59.8 \\
Moderate excessive sleepiness & 29 & 31.3 \\
Significant excessive sleepiness & 0 & 0 \\
\hline
\end{tabular}


T3 and between T2-T3 $(p<0.05)$ at the end of it. The ER has increased from the beginning of the shift till the end of it $(p<0.05)$.

During the task with positive subscripting (PS), the RT and ER have increased from the beginning to the end of the shift $(p=0.01)$. A simultaneous tendency to the increase of these two variables between T1 and T2 and a downward trend between T2 and T3 were also found during the test of negative cueing (NC).

The difference of RT was significant between T1 and T2 $(p=0.02)$; and nonsignificant between T1-T3 and T2-T3 $(p=0.285)$. No statistically significant difference was observed for the ER in the practice of this test (Table 3 ).

\section{Discussion}

The participation rate was $86 \%$. The refusal of participation has been explained by a large workload for certain departments (resuscitation, emergencies, pediatrics) and by lack of motivation to participate in this survey by some care agents. The decline of vigilance with an ascent of the error rate among fixed night staff has been highlighted in our study. In fact, sleep deprivation leads to a sleep debt among night workers estimated between 1 to 2 hours that causes an excessive sleepiness [29] [30] [31].

In our study, an excessive somnolence has been found among $53.26 \%$ of the care agents with an Epworth average score of $14.5 \pm 6$. These results differ from those reported in literature. In a comparative study of the neuro-physiological changes of attention and memorization among a group of healthy night workers, a group of night workers with sleep disorder and a group of day workers, Valentina G.; et al., have reported an Epworth average score respectively of $5.3 \pm 3.9$; $11.8 \pm 4$ and $4.7 \pm 2.8$ [32]. Somnolent subject has a deterioration of certain cognitive functions of frontal origin: attention and concentration are reduced; reflexes are slowed down, and decision is altered [33].

The high prevalence of an excessive daytime somnolence noted among our studied population can translate an accumulated sleep debt, what is correlated to a long home-hospital trip and socio-family constraints.

However, some authors reported an adaptation of workers to fixed night work [34]. This adaptation is related to a resistance to the desynchronization of the

Table 3. Objective evaluation of vigilance according to super Lab program.

\begin{tabular}{|c|c|c|c|c|c|c|}
\hline & \multicolumn{6}{|c|}{ Period of evaluation } \\
\hline & \multicolumn{3}{|c|}{ Reaction time (RT) } & \multicolumn{3}{|c|}{ Errors rate (ER) } \\
\hline & $\mathrm{T} 1$ & $\mathrm{~T} 2$ & T3 & $\mathrm{T} 1$ & $\mathrm{~T} 2$ & T3 \\
\hline $\begin{array}{c}\text { The task of } \\
\text { simple reaction }\end{array}$ & $355 \pm 67.4 \mathrm{~ms}$ & $359 \pm 53.1 \mathrm{~ms}$ & $350 \pm 51.4 \mathrm{~ms}$ & $2 \pm 2.9$ & $3.2 \pm 1.6$ & 3. \pm 2.3 \\
\hline $\begin{array}{c}\text { The task of positive } \\
\text { subscripting }\end{array}$ & $350 \pm 101 \mathrm{~ms}$ & $404 \pm 53.5 \mathrm{~ms}$ & $390 \pm 44 \mathrm{~ms}$ & $1.8 \pm 0.7$ & $4.5 \pm 3.2$ & $16.5 \pm 5.7$ \\
\hline $\begin{array}{c}\text { The task of negative } \\
\text { subscripting }\end{array}$ & $450 \pm 44.8 \mathrm{~ms}$ & $500 \pm 63.8 \mathrm{~ms}$ & $400 \pm 66 \mathrm{~ms}$ & $14 \pm 14.7$ & $16.5 \pm 15$ & $13 \pm 8$ \\
\hline
\end{tabular}

T1: the beginning of the night shift (between19 - 20'o clock), T2: mid-time of the shift (between 24 - 1'o clocks), T3: the end of it (5 - 6'o clocks). ms: millisecond. 
biological clock. This resistance is fragile; it is broken as soon as the subject resumes a normal circadian rhythm during the vacations for example. The young age, the circadian typology and the motivation to work at night represented the major factors involved in the adaptation phenomenon to fixed night shift [35].

In our study, an extension of the RT between the beginning and half-time night work has been found, followed by a decline of the RT at the end of the shift.

Within the framework of a collective organization of working time, the majority of the staff participating in the objective evaluation of vigilance has had an episode of rest during the second half of the shift. The improvement of the state of objectified vigilance can be attributed to the refreshing effect of night nap. The compensatory effect of this rest on vigilance is also reported by several authors [35] [36].

The increase of ER between the beginning and the end of the night shift could be attributed to a decline in cognitive functions of the medical staff. So that, the organization of work and the planning of tasks at night in a care setting must take into account the decline in cognitive performance of the night staff in order to ensure a good quality of care and prevent the accidental risk for the patient and the staff.

This study has some limits. Objective evaluation of alertness has been carried out by the Super Lab program. Although its use is simple and easy to understand, the effect of practice and learning could constitute a bias while studying the variation of vigilance. This test was conducted with a representative sample of the study population but the number of staff who participated in the objective evaluation of alertness was low. Despite these limits, this study can be an outlet for more detailed studies.

\section{Conclusions}

Because of requirements of continuity of care, night work is inevitable in a hospital work. This rhythm of work obliges the paramedical staff to contrast their biological clock and disturb their internal and external sleep synchronizers.

This study has objectified a decline of alertness with an ascent of the error rate among fixed night workers that could have implications not only on health of care agents but also on the safety of patients. So, it seems necessary to reflect on the work organizations and to detect medical personnel as soon as possible, which is non-suitable for night work through regular medical checkups.

\section{Conflicts of Interest}

The authors declare that they have no conflicts of interest related to this article.

\section{References}

[1] Sanches, I., Teixeira, F., Santos, J.M. and Ferreira, A.F. (2015) Effects of Acute Sleep Deprivation Resulting from Night Shift Work on Young Doctors. Acta Médica Portuguesa, 28, 457-462. https://doi.org/10.20344/amp.5777 
[2] Neylan, T.C., Metzler, T.J., Henn-Haase, C., Blank, Y., Tarasovsky, G., McCaslin, S.E., et al. (2010) Prior Night Sleep Duration Is Associated with Psychomotor Vigilance in a Healthy Sample of Police Academy Recruits. Chronobiology International, 27, 1493-1508. https://doi.org/10.3109/07420528.2010.504992

[3] Wright, K.P., Hull, J.T. and Czeisler, C.A. (2002) Relationship between Alertness, Performance, and Body Temperature in Humans. American Journal of Physiology, 283, 1370-1377.

[4] Pilcher, J.J. and Huffcutt, A.I. (1996) Effects of Sleep Deprivation on Performance: A Meta-Analysis. Sleep, 19, 318-326.

[5] Goel, N., Rao, H., Durmer, J. and Dinges, D.F. (2009) Neurocognitive Consequences of Sleep Deprivation. Seminars in Neurology, 29, 320-339.

https://doi.org/10.1055/s-0029-1237117

[6] Thomas, M., Sing, H., Belenky, G., Holcomb, H., Mayberg, H., Dannais, R., et al. (2000) Neural Basis of Alertness and Cognitive Performance Impairments during Sleepiness. Journal of Sleep Research, 9, 335-352.

https://doi.org/10.1046/j.1365-2869.2000.00225.x

[7] Pomplun, M., Silva, E., Ronda, J.M., Cain, S.W., Munch, M.Y., Czeisler, C.A., et al. (2012) The Effects of Circadian Phase, Time Awake, and Imposed Sleep Restriction on Performing Complex Visual Tasks: Evidence from Comparative Visual Search. Journal of Vision, 12, 14. https://doi.org/10.1167/12.7.14

[8] Van Dongen, H.P.A., Maislin, G., Mullington, J.M. and Dinges, D.F. (2003) The Cumulative Cost of Additional Wakefulness: Dose-Response Effects on Neurobehavioral Functions and Sleep Physiology from Chronic Sleep Restriction and Total Sleep Deprivation. Sleep, 26, 117-126.

[9] Wyatt, J.K., Ritz-De Cecco, A., Czeisler, C.A. and Dijk, D.J. (1999) Circadian Temperature and Melatonin Rhythms, Sleep, and Neurobehavioral Function in Humans Living on a 20-H Day. American Journal of Physiology, 277, R1152-R1163.

[10] Merijanti, L.T., Samara, D., Tandean, R. and Harrianto, R. (2008) The Role of Night Shift Work on Blood Pressure among Healthy Female Nurses. Universa Medicina, 27, 65-71.

[11] Liu, Y. and Tanaka, H. (2002) The Fukuoka Heart Study Group. Overtime Work, Insufficient Sleep, and Risk of Non-Fatal Acute Myocardial Infarction in Japanese Men. Occupational and Environmental Medicine, 59, 447-451. https://doi.org/10.1136/oem.59.7.447

[12] Gangwisch, J.E., Heymsfield, S.B., Boden-Albala, B., Buijs, R.M., Kreier, F., Pickering, T.G., et al. (2006) Short Sleep Duration as a Risk Factor for Hypertension: Analysis of the First National Health and Nutrition Examination Survey. Hypertension, 47, 833-839. https://doi.org/10.1161/01.HYP.0000217362.34748.e0

[13] Taheri, S., Lin, L., Austin, D., Young, T. and Mignot, E. (2004) Short Sleep Duration is Associated with Reduced Leptin, Elevated Ghrelin, and Increased Body Mass Index. PLOS Medicine, 1, e62. https://doi.org/10.1371/journal.pmed.0010062

[14] Knutson, K.L. and Van Cauter, E. (2008) Associations between Sleep Loss and Increased Risk of Obesity and Diabetes. Annals of the New York Academy of Sciences, 1129, 287-304. https://doi.org/10.1196/annals.1417.033

[15] Onen, S.H., Onen, F., Courpron, P. and Dubray, C. (2005) How Pain and Analgesics Disturb Sleep. The Clinical Journal of Pain, 21, 422-431. https://doi.org/10.1097/01.ajp.0000129757.31856.f7

[16] Dinges, D.F. (1995) An Overview of Sleepiness and Accidents. Journal of Sleep Research, 4, 4-14. https://doi.org/10.1111/j.1365-2869.1995.tb00220.x

[17] Centers for Disease Control and Prevention (CDC) (2009) Perceived Insufficient 
Rest or Sleep among Adults-United States, 2008. Morbidity and Mortality Weekly Report, 58, 1175-1179.

[18] Reddy, R., Guntupalli, K., Alapat, P., Surani, S., Casturi, L. and Subramanian, S. (2009) Sleepiness in Medical ICU Residents. Chest, 135, 81-85. https://doi.org/10.1378/chest.08-0821

[19] Surani, S., Hesselbacher, S., Guntupalli, B., Surani, S. and Subramanian, S. (2015) Sleep Quality and Vigilance Differ among Inpatient Nurses Based on the Unit Setting and Shift Worked. Journal of Patient Safety, 11, 215-220. https://doi.org/10.1097/PTS.0000000000000089

[20] Friedman, R.C., Bigger, J.T. and Kornfield, D.S. (1971) The Intern and Sleep Loss. The New England Journal of Medicine, 285, 201-203. https://doi.org/10.1056/NEJM197107222850405

[21] Friedman, R.C., Kornfeld, D.S. and Bigger, T.J. (1973) Psychological Problems Associated with Sleep Deprivation in Interns. Journal of Medical Education, 48, 436-441.

[22] Goldman, L.I., McDonough, M.T. and Rosemond, G.P. (1972) Stresses Affecting Surgical Performance and Learning: I. Correlation of Heart Rate, Electrocardiogram, and Operation Simultaneously Recorded on Videotapes. Journal of Surgical Research, 12, 83-86. https://doi.org/10.1016/0022-4804(72)90125-4

[23] Stratégies de diagnostic de l'exposition des travailleurs aux substances chimiques. Études et recherches RAPPORT R-665. http://www.irsst.qc.ca/

[24] Johns, M. (1991) A New Method for Measuring Daytime Sleepiness: The Epworth Sleepiness Scale. Sleep, 14, 540-545. https://doi.org/10.1093/sleep/14.6.540

[25] Chervin, R.D., Aldrich, M.S., Pickett, R. and Guilleminault, C. (1997) Comparison of the Results of the Epworth Sleepiness Scale and the Multiple Sleep Latency Test. Journal of Psychosomatic Research, 42, 145-155. https://doi.org/10.1016/S0022-3999(96)00239-5

[26] Doucet, J. and Kerkhofs, M. (2004) Exploration du sommeil chez l'adulte et l'adolescent. EMC-Psychiatrie, 1, 176-187.

[27] Kenji, F., Hiroyuki, A., Isao, O., Takashi, H., Masaya, T., Akinori, N., Yasumasa, O., Kosuke, K. and Takanobu, H. (2006) Perceived Sleepness on Non-Shift Working Men in Two Different Types of Work Organization. Journal of Occupational Health, 48, 230-238. https://doi.org/10.1539/joh.48.230

[28] Salim, S.S., Raymond, A., Maqsood, A. and Joseph, V. (2007) Sleepiness in Medical Residents: Impact of Mandated Reduction in Work Hours. Sleep Medicine, 8, 9093. https://doi.org/10.1016/j.sleep.2006.08.018

[29] Bayon, V., Benzekri-Le, L.A., Prévôt, E., Choudat, D. and Léger, D. (2008) Surveillance à adopter pour les travailleurs postés et de nuit. Archives des Maladies Professionnelles et de 1 Environnement, 69, 695-707.

[30] Léger, D., Bayon, V., Metlaine, A., Prevot, E., Didier, M.C. and Choudat, D. (2009) Horloge biologique, sommeil et conséquences médicales du travail posté. Archives des Maladies Professionnelles et de 1 Environnement, 70, 246-252. https://doi.org/10.1016/j.admp.2009.01.007

[31] Oken, B.S., Salinsky, M.C. and Elsas, S.M. (2006) Vigilance, Alertness, or Sustained Attention: Physiological Basis and Measurement. Clinical Neurophysiology, 117, 1885-1901. https://doi.org/10.1016/j.clinph.2006.01.017

[32] Gumenyuk, V., Roth, T., Korzyukov, O., Jefferson, C., Kick, A., Spear, L., Tepley, N. and Drake, C.L. (2010) Shift Work Sleep Disorder Is Associated with an Attenuated Brain Response of Sensory Memory and an Increased Brain Response to Novelty: An ERP Study. Sleep, 33, 703-713. 
[33] Arnulf, I. (2011) Evaluation de la somnolence et de la vigilance. http://www.afvp.info/vietnamien/galleryUpload/883_Chapitre\%204.pdf

[34] Debbabi, F., Chatti, S., Magroun, I., Maalel, O., Mahjoub, H. and Mrizak, N. (2004) Le travail de nuit: Ses répercussions sur la santé du personnel hospitalier. Archives des Maladies Professionnelles et de 1 Environnement, 65, 489-492.

[35] Torbjtirn, A. (1998) Shift Work and Disturbed Sleep/Wakefulness. Sleep Medicine Reviews, 2, 117-128. https://doi.org/10.1016/S1087-0792(98)90004-1

[36] Schweitzer, P.K., Randazzo, A.C., Stone, K., Erman, M. and Walsh, J.K. (2006) Laboratory and Field Studies of Naps and Caffeine as Practical Countermeasures for Sleep-Wake Problems Associated with Night Work. Sleep, 29, 39-50.

Submit or recommend next manuscript to SCIRP and we will provide best service for you:

Accepting pre-submission inquiries through Email, Facebook, LinkedIn, Twitter, etc. A wide selection of journals (inclusive of 9 subjects, more than 200 journals)

Providing 24-hour high-quality service

User-friendly online submission system

Fair and swift peer-review system

Efficient typesetting and proofreading procedure

Display of the result of downloads and visits, as well as the number of cited articles

Maximum dissemination of your research work

Submit your manuscript at: http://papersubmission.scirp.org/

Or contact ojn@scirp.org 